\title{
Claves antropológicas del pensamiento de Clemente de Alejandría
}

\author{
Anthropological keys to the thought of Clement of Alexandria
}

\author{
Ángel Gerónimo Llopis \\ Doctor en Humanidades y Ciencias Sociales \\ Universidad Católica de Valencia \\ angelgeronimollopis@gmail.com \\ Fecha de recepción: 30/04/2020 \\ Fecha de aceptación: 13/07/2020
}

Cómo citar este artículo: A. Gerónimo. “Claves antropológicas del pensamiento de Clemente de Alejandría” en Palabra y Razón. Revista de Teología, Filosofía y Ciencias de la Religión. No 17 Julio 2020 , pp 76-99 https://doi.org/10.29035/pyr.17.76

Resumen: Clemente de Alejandría es considerado como el fundador de la filosofía cristiana, demostrando que fe y filosofía son ciertamente complementarias. Nacido a mediados del siglo II, inauguró la convergencia y alianza entre el cristianismo y la cultura griega. Gran parte de sus obras tienen un valor incalculable dentro de la literatura eclesiástica y de la filosofía cristiana de los primeros siglos de la Iglesia. Este estudio aborda con profundidad la visión que el autor alejandrino tenía sobre el hombre. Temas como la disposición alma-cuerpo, el fin del hombre a alcanzar su propia identidad como imagen de Dios y a desarrollar la llamada a ser semejante a Dios, la libertad o la apertura a la verdad, centran el contenido de este trabajo y nos llevan a conocer las claves más importantes de la antropología de Clemente de Alejandría.

Palabras claves: Clemente de Alejandría / antropología / cristianismo / libertad / verdad

Abstract: Clement of Alexandria is considered the founder of Christian philosophy, proving that faith and philosophy are certainly complementary. Born in the middle of the second century, inaugurated the convergence and alliance between Christianity and Greek culture. Much of his works have an incalculable value in ecclesiastical literature and Christian philosophy of the early centuries of the Church. This study addresses in depth the vision that the Alexandrian author had about man. Topics such as the soul-body disposition, the end of man to reach his own identity as an image of God and to develop the call to be like God, freedom or openness to the truth, they center the content of this work and lead us to know the most important keys of the anthropology of Clement of Alexandria.

Keyswords: Clement of Alexandria / anthropology / christianity / freedom / true 
A. Gerónimo. "Claves antropológicas del pensamiento de Clemente de Alejandría" en Palabra y Razón. Revista de Teología, Filosofia y Ciencias de la Religión. $\mathrm{N}^{\circ} 17$ Julio 2020, pp 76-99 https://doi.org/10.29035/pyr.17.76

\section{Introducción}

Clemente de Alejandría, nacido a mediados del siglo II, inauguró la filosofía cristiana, dejando patente que fe y filosofía son totalmente complementarias. Por eso mismo, Clemente de Alejandría atribuía al Evangelio el título de la verdadera filosofía, e interpretaba la filosofía griega como una instrucción propedéutica a la fe cristiana y una preparación para el Evangelio ${ }^{1}$. Para el autor alejandrino, si bien es cierto que la filosofía griega no puede alcanzar la verdad en su totalidad, prepara el camino de la verdad de la forma más solemne.

El estudio del siglo II constituye uno de los enigmas más difíciles de interpretar en la historia del cristianismo, y a la vez, resulta determinante $\mathrm{y}$ trascendental para la configuración del pensamiento cristiano. El trabajo intelectual de los cristianos de este siglo afronta una doble tarea: en primer lugar, conservar en un ambiente sincretista la fe revelada en Cristo, y en segundo lugar, adaptar la explicación y la comprensión de esta fe a la perspectiva intelectual y cultural de aquel tiempo ${ }^{2}$. Se trata, en nuestra opinión, de una tarea semejante por muchos aspectos a la de nuestra época: un tiempo de relativismo moral, de diálogo con un mundo pluralista, donde el hombre se encuentra en constante situación de búsqueda.

El diálogo cristianismo-helenismo abarcó una gran parte de las cuestiones del saber humano: durante el siglo el debate se centró de forma habitual en torno a la cuestión humana de la salvación. Por otra parte, un problema común a los cristianos de aquel siglo y a los cristianos del nuestro es el de la búsqueda de la propia identidad humana y cristiana en el seno de nuestra sociedad. Aquellos primeros pensadores cristianos se interrogaron a sí mismos acerca del sentido de la existencia humana, sobre la novedad que aportaba el cristianismo. A lo largo del siglo II se dieron una serie de intentos de respuesta a estos interrogantes: Justino, Melitón de Sardes, Atenágoras y Teófilo Antioqueno entre otros, trataron de llegar a definir la identidad propia del cristiano. En la segunda mitad del siglo II, Irineo, Tertuliano y Clemente de Alejandría prosiguen las vías abiertas por sus precursores, logrando así trazar de forma profunda y decisiva las claves de una antropología cristiana sistemática.

Así, pues ¿qué respuesta da Clemente de Alejandría a la antigua y perenne pregunta qué es el hombre? El presente trabajo proporciona una reflexión sobre la concepción del hombre que se desprende de los escritos

1 Cf. J. BELDA, Historia de la Teología, Palabra: Madrid, 2010. p. 28.

2 Cf. J. M. DALMAU - S. VERGÉS, Dios revelado por Cristo, BAC: Madrid, 1969, p. 215. 
A. Gerónimo. "Claves antropológicas del pensamiento de Clemente de Alejandría" en Palabra y Razón. Revista de Teología, Filosofia y Ciencias de la Religión. $\mathrm{N}^{\circ} 17$ Julio 2020, pp 76-99 https://doi.org/10.29035/pyr.17.76

y obras del maestro de Alejandría.

La antropología de Clemente se ajusta en buena medida a la de la tradición clásica, pero con la aportación del elemento bíblico y cristiano. En esta antropología destaca de alguna manera la libertad humana, lo cual "es un rasgo inequívoco y constante de los pensadores cristianos"3.

Clemente defiende la unidad del alma con el cuerpo con más fuerza que las escuelas platónicas, y esto gracias al cristianismo. Por otra parte, la base filosófica que sigue es una síntesis de platonismo y estoicismo, en relación y dependencia de los textos bíblicos antropológicos. De este modo, afirma Sanguineti, que es importante estudiar a Clemente en sí mismo, eludiendo la tipificación de "escuela alejandrina", que está centralizada de un modo excesivo en el pensamiento de Orígenes y que, en todo caso, corre el riesgo de perder los matices propios de nuestro autor y de acercarse a él de un modo simplificado ${ }^{4}$.

\section{La disposición alma-cuerpo}

Además del cuerpo, el principio activo unitario y estructurante de la persona humana fue llamado "alma" por los filósofos clásicos ${ }^{5}$. La antropología cristiana distingue -desde sus comienzos- dos niveles diferentes en la persona humana. Al mismo tiempo, empieza, sobre todo con los alejandrinos, a asentarse en la doctrina platónica del alma, para delimitar su toma de posición respecto a los problemas filosóficos. En este sentido, la oposición de las Escrituras entre el hombre exterior y el hombre interior, el hombre carnal y el hombre espiritual, parecía a los ojos de Clemente - del mismo modo que en otros Padres-, que respondía bien a la distinción griega entre el alma y el cuerpo ${ }^{6}$.

El tema de la constitución humana en alma (espíritu) y cuerpo en Clemente de Alejandría, resulta bastante dificultoso a la hora de ser estudiado y merece un análisis aparte 7 . De hecho, dice Fernández Ardanaz que "estudiar la antropología de Clemente es topar continuamente con dificultades sin fin. Sobre todo cuando se la considera aisladamente, sin

3 J. J. SANGUINETI, La antropología educativa de Clemente Alejandrino. El giro del paganismo al cristianismo, EUNSA: Pamplona, 2003, p. 234.

4 Cf. J. J. SANGUINETI, La antropología educativa de Clemente Alejandrino..., p. 234.

5 Cf. J. J. SANGUINETI, Neurociencia y filosofía del hombre, Palabra: Madrid, 2014, p. 235.

6 Cf. T. SPIDLIK, La espiritualidad del oriente cristiano, Monte Carmelo: Burgos, 2004, p. 124.

7 Este tema lo estudian de forma exhaustiva L. F. LADARIA, El Espiritu en Clemente Alejandrino. Estudio teológico-antropológico, Estudios 16: Madrid, 1980, pp. 114-165; S. FERNÁNDEZ ARDANAZ, Génesis y Anagennesis. Fundamentos de la antropología cristiana según Clemente de Alejandría, Eset: Vitoria, 1990. 
A. Gerónimo. "Claves antropológicas del pensamiento de Clemente de Alejandría" en Palabra y Razón. Revista de Teología, Filosofia y Ciencias de la Religión. Nº 17 Julio 2020, pp 76-99 https://doi.org/10.29035/pyr.17.76

relación al esfuerzo intelectual de sus predecesores durante el siglo II"8.

Al igual que en otros temas, se encuentra en el Alejandrino una fluctuación de sentidos en la utilización de las palabras alma, espíritu, cuerpo, carne o razón, lo que da lugar a una antropología, a veces, poco coherente en algunos aspectos. Clemente suele definir al hombre como un compuesto de alma y cuerpo, aunque en algunos casos se refiere al alma o al espíritu para expresar al hombre como tal, por lo que podría aparecer una trilogía de carne, o cuerpo, alma y espíritu ${ }^{9}$. De este modo lo explica Sanguineti:

"En Clemente aparecen los binomios carnal-espiritual (en su sentido paulino), alma/cuerpo y, aunque algunas veces parezca aludir a la tricotomía cuerpo/alma/espíritu, en principio su vocabulario es dicotómico. La noción de espíritu en algunos casos señala la acción sobrenatural del Espíritu Santo, y la carne o lo carnal, en la línea de san Pablo, indica en ocasiones lo relacionado con el pecado, o también lo corruptible del hombre, sitio de nuestro peregrinar hacia el cielo (otro sentido igualmente paulino)" ${ }^{\prime 10}$.

Bajo el punto de vista de Clemente, el alma es la parte del ser humano que goza de superioridad, pero, no obstante, el cuerpo es bueno, en contra de la visión pesimista de los gnósticos.

"Está, pues, admitido que el alma es la parte superior del hombre, y el cuerpo la inferior. Pero ni el alma es buena por naturaleza, ni tampoco es naturalmente malo el cuerpo; y nada de lo que no es bueno es por eso inmediatamente malo. Existen, en efecto, cosas intermedias, e incluso entre ellas hay cosas que son preferibles y cosas que son rechazables. Era, pues, oportuno que el compuesto humano, que forma parte del ámbito de lo sensible, estuviera constituido de elementos diversos, como cuerpo y alma, pero no contrario" 11 .

Encontramos en el capítulo 16 de Stromata VI, uno de los textos de Clemente que más aportaciones antropológicas comprende:

"El alma es añadida y antes se inserta lo que tiene función hegemónica, por lo que razonamos, no engendrado mediante la cimentación seminal, para así añadir, sin el concurso de ésta, el número diez (de las partes humanas),

8 S. FERNÁNDEZ ARDANAZ, Génesis y Anagennesis..., p. 73.

9 Cf. E. DUSSEL, El humanismo helénico, Eudeba: Buenos Aires, 1975, p. 77; cf. J. J. SANGUINETI, La antropología educativa de Clemente Alejandrino... p. 235.

10 J. J. SANGUINETI, La antropología educativa de Clemente Alejandrino..., p. 235.

11 CLEMENTE DE ALEJANDRÍA, Stromata, IV, 164, 3-5 (Se utiliza la edición bilingüe de M. MERINO, Stromata IV-V. Martirio cristiano e investigación sobre Dios, Ciudad Nueva, Fuentes Patrísticas 15: Madrid, 2003, p. 295). 
mediante las cuales se realiza toda la actividad del hombre. Hecho el hombre inmediatamente en esta disposición, comienza a vivir a partir de las experiencias sensibles. Ahora bien, nosotros afirmamos que lo racional y lo que tiene función de guía es para el ser vivo causa de la formación, pero también que el elemento irracional llegue a ser espiritual y forme parte del alma. En seguida, el espíritu carnal, que se mueve rápidamente y está en todo mediante los sentidos y el resto del cuerpo y que lleva los impulsos de las pasiones del cuerpo, recibe la fuerza vital en la que se contiene la facultad de nutrición, de crecimiento y en general de todo movimiento. Pero lo que tiene función de guía posee la facultad decisoria, alrededor de la cual se encuentran la investigación, el aprendizaje y la gnosis. Así, no obstante, lo que tiene función de guía coordina la atribución de todo a la unidad y por ello el hombre vive y con un modo propio. Así pues, el hombre siente por medio del espíritu corpóreo, y desea, goza, se enoja, se alimenta y crece; precisamente por él conduce las acciones relativas al pensamiento y a la inteligencia, y una vez dominadas las pasiones, reina lo que tienen función hegemónica" 12 .

Este texto muestra cómo las funciones sensitivas del ser humano se atribuyen a un "espíritu o alma corpórea, o carnal" que asimila el organismo y encabeza su generación y formación, siendo también el principio de las sensaciones. Está hablando de lo que Aristóteles ya distinguía como alma sensitiva y vegetativa. Sin embargo, por encima de este principio vital, Clemente de Alejandría, influenciado netamente por el estoicismo, distingue "la parte del alma hegemónica"13, la que hace de guía, con la que razonamos. Esta parte no generada por la emisión seminal, es poseedora de la libre facultad de elección y en ella residen los procesos de investigación, aprendizaje o gnosis. De este modo, en la plasmación del embrión humano Clemente acepta de manera ecléptica las ideas médicas aristotélicas y sobre todo estoicas ${ }^{14}$. En palabras de Berraondo, para los estoicos "la facultad de razonar representa la parte hegemónica o directriz, en donde tienen lugar las representaciones y las inclinaciones; desde ella se emite la palabra y se encuentra en el corazón"15.

Así pues, la parte hegemónica es el intelecto o razón, raíz de la libertad, principio no corruptible que para Clemente posee una especial

12 CLEMENTE DE ALEJANDRÍA, Stromata, VI, 135, 1 - 136, 1 (Se utiliza la edición bilingüe de M. MERINO, Stromata VI-VIII. Vida intelectual y religiosa del cristiano, Ciudad Nueva, Fuentes Patrísticas 17: Madrid, 2005, pp. 275-277).

13 Cf. CLEMENTE DE ALEJANDRÍA, Stromata, VI, 134, 2 (A partir de ahora se abreviará de este modo: FuP 17, p. 275).

14 Cf. M. SPANNEUT, Le Stoïcisme des Pères de l'Église de Clément de Rome à Clément d'Alexandrie, Patristica Sorboniensia: Paris, 1957, pp. 167-170.

15 J. BERRAONDO, El Estoicismo. La limitación interna del Sistema, Montesinos: Barcelona, 1992, p. 133. 
relación con Dios. Esto se debe gracias a su origen, por un lado, y por ser una imagen de $\operatorname{Dios}^{16}$, por otro. Por esta razón constituye el lugar propio donde Dios se manifiesta al comunicarse con los hombres. Este principio superior, aunque esté íntimamente asociado al cuerpo, es y actúa por sí mismo ${ }^{17}$.

Unido a la supremacía del espíritu, el maestro alejandrino defiende el valor del cuerpo, motivado por su crítica a los gnósticos y por su pensamiento del Logos encarnado. Así, es llamativa la crítica que el propio Clemente realiza contra algunos que pretendían entregarse directamente a sus perseguidores para morir: "mas, puesto que esos ${ }^{18}$ de falso nombre deshonran el cuerpo, deberían saber también que la buena disposición favorece la reflexión, la buena cualidad natural"19. En este caso, Clemente -en contra de los marcionistas-, parece tener clara su postura: la muerte afecta al ser humano material por naturaleza, y no por castigo; Cristo no nos librará de ella, sino que, más bien al contrario, mediante la muerte física nos liberará y nos ofrecerá la salvación ${ }^{20}$. Del mismo modo, también el Alejandrino muestra firmemente la interacción mutua de cuerpo y alma en el hombre ${ }^{21}$.

El cuerpo humano se encuentra estructuralmente preparado para contener la actividad del espíritu, por eso puede albergar dentro de sí al Espíritu Santo. En este sentido manifiesta Clemente:

"Por consiguiente, los que sin razón lanzan invectivas contra la creación y censuran el cuerpo, tampoco ven que la constitución del hombre ha sido dispuesta en posición erecta para contemplar el cielo, ni que la organización de los sentidos está dirigida a la gnosis y que los miembros y las partes (del cuerpo) están dispuestos adecuadamente hacia la belleza, no al placer. Por ello, esta morada acogedora del alma, preciosísima para Dios, es tenida digna del Espíritu Santo, gracias a la santificación del alma y del cuerpo a la vez, y llevada a perfección por la reconciliación del Salvador"22.

Desde la óptica de Clemente, el valor del cuerpo exige su santificación, y es que, para él, una santidad netamente espiritual carece de

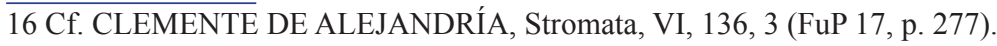

17 Cf. J. J. SANGUINETI, La antropología educativa de Clemente Alejandrino..., p. 236.

18 Refiriéndose a algunos cristianos.

19 CLEMENTE DE ALEJANDRÍA, Stromata, IV, 17, 4 (FuP 15, p. 81).

20 Cf. A. ORBE, "Los primeros herejes ante la persecución”, en Estudios Valentinianos, vol. V, Analecta Gregoriana 83: Roma, 1956, pp. 12-46.

21 Cf. S. FERNÁNDEZ ARDANAZ, Génesis y Anagennesis..., p. 84; cf. M. SPANNEUT, Le

Stoïcisme..., p. 369.

22 CLEMENTE DE ALEJANDRÍA, Stromata, IV, 163, 1-2 (FuP 15, p. 293). 
valor humano. De hecho, no duda en afirmar que “es Él, Jesús, el médico de nuestro cuerpo y de nuestra alma, del hombre entero"23. Del mismo modo "conviene, pues, que nosotros mismos seamos santos no sólo en el espíritu, sino también en las costumbres, en la vida y en el cuerpo" ${ }^{24}$. El maestro de Alejandría cristianiza el principio platónico de la reciprocidad de los elementos que componen el ser humano, evidenciando que la asociación del cuerpo a la santificación del cristiano es una de las ideas maestras en Clemente. Al mismo tiempo Clemente mantuvo la idea de que Cristo asumió la carne para mostrarnos la posibilidad de santificar la misma carne: "En efecto, lo que Él era no fue visto por quienes no podían por la debilidad de la carne, pero asumiendo Él una carne sensible demuestra lo que es posible a los hombres por la obediencia a los mandamientos" ${ }^{25}$.

En la visión del autor cristiano, el agua del Bautismo regenera y ennoblece la carne ${ }^{26}$, y de modo parecido la Eucaristía, a la que considera gracia laudable y hermosa, que santifica el cuerpo y el alma de quienes la reciben con $\mathrm{fe}^{27}$, y que es otro componente que permite a Clemente percibir la unión del Logos con el cuerpo del cristiano en quien habita el Espíritu. A través del don de la Eucaristía, el Espíritu inhabita en el alma que bajo él subyace, y la carne (se une) al Logos, por la que el Logos se hizo carne ${ }^{28}$.

En otro orden de cosas, para Clemente existe una gradación de los diferentes momentos de la esencia humana, es decir, considera la existencia de distintos niveles antropológicos. Dussel afirma que "Clemente ha distinguido, entonces, en primer lugar un orden que llama del cuerpo o carne; se trata del nivel de los cinco sentidos, la voz -como lengua o mecanismo fónico del lenguaje-, y el instinto sexual". ${ }^{29}$ También el alma ${ }^{30}$ de la que se habla en este contexto es la facultad anímica de la formación. Según Dussel, "esta alma con los siete primeros elementos constituye lo que para Platón sería el cuerpo a los niveles de las almas inferiores"31. Otro momento, según el Alejandrino, era el nous o entendimiento. Por medio de

23 CLEMENTE DE ALEJANDRÍA, El Pedagogo, III, 98, 2 (Se utiliza la edición bilingüe de M. MERINO y E. REDONDO, El Pedagogo, Ciudad Nueva, Fuentes Patrísticas 5: Madrid, 1994, p. 657).

24 CLEMENTE DE ALEJANDRÍA, Stromata, III, 47, 1 (Se utiliza la edición bilingüe de M. MERINO, Stromata II-III. Conocimiento religioso y continencia auténtica, Ciudad Nueva, Fuentes Patrísticas 10: Madrid, 1998, pp. 383-385).

25 CLEMENTE DE ALEJANDRÍA, Stromata, VII, 8, 6 (FuP 17, pp. 347-349).

26 Cf. CLEMENTE DE ALEJANDRÍA, El Pedagogo, II, 118, 5 (FuP 5, p. 485).

27 Cf. CLEMENTE DE ALEJANDRÍA, El Pedagogo, II, 20, 1 (FuP 5, pp. 319-321).

28 Cf. CLEMENTE DE ALEJANDRÍA, El Pedagogo., II, 20, 1 (FuP 5, pp. 319-321).

29 E. DUSSEL, El humanismo helénico..., p. 78.

30 Cf. CLEMENTE DE ALEJANDRÍA, Stromata, IV, 163, 1-2 (FuP 15, 293).

31 E. DUSSEL, El humanismo helénico..., p. 78. 
este entendimiento el hombre es imagen de Dios. Esto puede observarse cuando Clemente dice al respecto:

"El Logos de Dios es inteligente, gracias a Él sólo en el hombre puede verse la imagen de la Inteligencia, y por la cual el varón bueno tiene forma y aspecto divinos en el alma, y a su vez Dios tiene forma humana. En efecto, la manera de ser de cada uno es la inteligencia, y es por la que nos caracterizamos. Por ello también quienes pecan contra el hombre son sacrílegos e impíos" ${ }^{\prime 32}$.

\section{El fin del hombre: alcanzar su propia identidad como imagen de Dios y desarrollar la llamada a hacerse semejante a Dios}

Una vez constituido el hombre como persona, cuya estructura es alma y cuerpo, es necesario dar otro paso más en el proceso de realización del ser humano. ¿Cuál es la finalidad de la existencia y del ser del hombre? ¿Cómo se realiza a sí mismo? ¿Cómo crece en su propio ser? Estas cuestiones, que afectan a lo profundo del hombre, son aspectos fundamentales en la antropología de Clemente.

En opinión de Sanguineti, para Clemente alejandrino, la vida del ser humano tiene sentido entendida con una orientación esencial hacia el mismo Dios por medio del conocimiento y del amor, que transforman al hombre hasta hacerlo semejante a Él, en la perspectiva de la participación de criatura redimida ${ }^{33}$. Así pues, Dussel es bastante conciso al afirmar de Clemente:

"Toda su reflexión puede centrarse en la dialéctica establecida entre las nociones de imagen (eikón) y semejanza (homoiosis), que desde ahora se transformarán en estructura técnica de la antropología de la cristiandad oriental. Esta distinción ya efectuada por Ireneo, se inspira por un lado en la Biblia y por otra en Platón" ${ }^{\prime 34}$.

Clemente de Alejandría incide temáticamente sobre esta cuestión en los capítulos 19-22 de Stromata II. Precisamente en el capítulo 21 estudia detenidamente el pensamiento de otros filósofos: los estoicos establecen que el fin del hombre es vivir conforme a la naturaleza o la razón. Los epicúreos defenderán que el fin del ser humano o la felicidad residen en el placer o el bienestar, o -si esto no se puede conseguir-, en la ausencia de dolor. Los aristotélicos, por su parte, lo sitúan en las virtudes,

32 E. DUSSEL, El humanismo helénico..., p. 78.

33 E. DUSSEL, El humanismo helénico..., p. 78.

34 E. DUSSEL, El humanismo helénico..., p. 78. 
A. Gerónimo. "Claves antropológicas del pensamiento de Clemente de Alejandría" en Palabra y Razón. Revista de Teología, Filosofia y Ciencias de la Religión. $\mathrm{N}^{\circ} 17$ Julio 2020, pp 76-99 https://doi.org/10.29035/pyr.17.76

y otros filósofos han hablado de temas tan diversos como la paz, la alegría, la ciencia, la contemplación, el equilibrio interior, la autosuficiencia, etc.

Por otra parte, nuestro autor, en el capítulo 22, se fija en la finalidad de la vida humana para los académicos, prestando una atención especial a Platón, -filósofo que para Clemente vio con mayor claridad y acierto el fin del hombre-.

La felicidad y el fin del ser humano se traducían para Platón en la asemejación a Dios en la santidad y en la justicia ${ }^{35}$. Clemente en Stromata II, 136, 6 cita a Platón en su obra Teeteto 176 b.

"Así que, el objetivo de la fe que Pablo pone es la semejanza con Dios, por cuanto es posible llegar ser justo y santo con sensatez, y como fin último, fundado sobre la fe, la realización de la promesa. De ahí nacen las fuentes de las teorías sobre el fin (humano) del que hemos hablado [...]"36.

El Alejandrino admite esta visión teleológica y la transporta al cristianismo. Efectivamente, el fin que pretendía alcanzar Platón es posible con la observancia de los mandamientos y el seguimiento e imitación de Cristo. El capítulo 19 de Stromata II trata este aspecto con diligencia.

"El filósofo Platón, cuando habla de felicidad como fin último, dice que eso es la semejanza a Dios en lo posible ${ }^{37}$; pero, o bien allí se encontró por casualidad con el dictamen de la Ley, (porque los espíritus grandes y despojados de pasiones consiguen la verdad, como dice el pitagórico Filón al explicar la historia de Moisés), o bien recibió la enseñanza de alguno de los sabios contemporáneos, en su constante ansia de aprender. En efecto, la Ley dice: Andad tras el Señor vuestro Dios, y cumplid los mandamientos. La ley llama a la semejanza (con Dios) seguimiento; y el hecho de seguirlo hace semejantes en lo que se puede. El Señor afirma ${ }^{38}$ : Sed misericordiosos y piadosos como vuestro Padre celestial es piadoso" 39 .

El fin del hombre es, como pretendía Platón, la semejanza con Dios en la medida en que puede llegar a serlo una criatura, pero esta finalidad se desarrolla ahora en el seguimiento a Cristo y a los mandamientos. Para Clemente sería entonces, un camino concreto que llevaría al hombre a este

35 Cf. J. J. SANGUINETI, La antropología educativa de Clemente Alejandrino..., p. 238.

36 CLEMENTE DE ALEJANDRÍA, Stromata, II, 136, 6 (FuP 10, p. 297).

37 Clemente relaciona aquí la fórmula de Platón con la cristiana, sin darse cuenta de que la platónica es de orden intelectual, mientras que la cristiana se desarrolla en el orden moral.

38 Lc 6, 36; cf. CLEMENTE DE ALEJANDRÍA, Stromata, V, 94, 6 (FuP 15, p. 485).

39 CLEMENTE DE ALEJANDRÍA, Stromata, II, 100, 3-4 (FuP 10, pp. 235-237). 
fin tan elevado. "Nuestro fin es la semejanza al regio Logos en la medida de lo posible, y de esta manera, al restablecimiento de la perfecta adopción filial a través del hijo" 40 . Por consiguiente, el fin del ser humano en la perspectiva clementina, en definitiva, es la plenitud de su filiación divina en Cristo $^{41}$.

Este fin al que está llamado el hombre no significa que no deba acceder a una serie de objetivos parciales correspondientes a la esfera de lo terreno: "el hombre ha nacido esencialmente para tener un conocimiento profundo de Dios, aunque también cultive campos, mida terrenos y filosofe" - quiero decir el hombre- ¿qué otra cosa diríamos que necesita sino contemplar lo divino ${ }^{43}$ ? Pero es necesario también - digo yo- contemplar la naturaleza humana"44. De modo que un fin conduce a otro fin, cuando se asume en su auténtico dinamismo y no se ponen como excluyentes, dañando así la unidad compleja del hombre ${ }^{45}$. Podemos leer en boca del mismo Clemente:

"Por tanto, en la vida contemplativa uno tiene cuidado de sí mismo mediante el culto que tributa a Dios y, mediante la purificación de sí mismo contempla a Dios, que es santo, de manera santa. La templanza, al meditar y contemplarse a sí misma sin interrupción, se asemeja en lo que puede a Dios" ${ }^{\prime 46}$.

En el pensamiento del Alejandrino, conocerse a sí mismo conduce a Dios mismo, y cuando el hombre conoce más profundamente a Cristo, puede llegar también a conocerse y a amarse mejor a sí mismo.

En la antropología clementina, el hombre está hecho a imagen de Dios, esto quiere decir que es imagen de Dios por su entendimiento ${ }^{47} \mathrm{o}$ racionalidad, principio de su misma perfección corpórea, pero la imagen primigenia es el Logos mismo de $\operatorname{Dios}^{48}$.

40 CLEMENTE DE ALEJANDRÍA, Stromata, II, 134, 2 (FuP 10, pp. 291-293).

41 Cf. J. J. SANGUINETI, La antropología educativa de Clemente Alejandrino..., p. 239.

42 CLEMENTE DE ALEJANDRÍA, Stromata, VI, 65, 6 (FuP 17, p. 167).

$43 \mathrm{C}$. Mondésert menciona que la actividad espiritual del hombre se fundamenta necesariamente en torno a la contemplación de Dios; cf. C. MONDÉSERT, "Vocabulaire de Clément d'Alexandrie: le mot logikós" en Recherches de science religieuse, Vol. 42, 1954, pp. 259.

44 CLEMENTE DE ALEJANDRÍA, El Pedagogo, I, 100, 3 (FuP 5, p. 271).

45 Cf. J. J. SANGUINETI, La antropología educativa de Clemente Alejandrino..., p. 239.

46 CLEMENTE DE ALEJANDRÍA, Stromata, IV, 152, 3 (FuP 15, p. 273).

47 Es interesante destacar cómo para Taciano el hombre era imagen de Dios gracias al Espíritu participado, mientras que para Ireneo, el hombre es imagen por su mismo cuerpo. Esta última tendencia es una tendencia mucho más semítica. Clemente, por el contrario, sólo indica la imagen de Dios en el hombre en su nivel intelectual; cf. E. DUSSEL, El humanismo helénico..., p. 79. 48 En opinión de Fernández Ardanaz, el hombre, hecho a imagen del Señor, realiza en sí la encarnación del Logos, se convierte en su templo sagrado, y se asemeja a los "dioses y ángeles". Es el hombre perfectamente constituido, realizado, que ha cumplido su proyecto de ser hombre a semejanza del Anthropos ejemplar. Este es el verdadero hombre, el hombre total; cf. S. FERNÁNDEZ ARDANAZ, Génesis y Anagennesis..., p. 307. 
Según Sanguineti, "Clemente relaciona esta prerrogativa con la autoconciencia humana"49. Así, el hombre ha de reconocer que es un ser mortal, que ha nacido hombre. Lo fundamental del autoconocimiento en el ser humano radica en la relación unitiva con Dios, de ahí que el arrepentimiento del pecado hace que el alma se vuelva a encontrar consigo misma y se autoconozca ${ }^{50}$.

Sin embargo, la "imagen" es dinámica, puesto que debe desarrollarse hasta alcanzar la plenitud (y purificarse de sus adulteraciones), y sólo entonces se hará "semejanza" de Dios en el sentido platónico. Así pues, es "imagen como el hombre creado, semejanza como el proceso de divinización" 51 . La tensión entre la "imagen" y la "semejanza" marca el desarrollo teleológico del hombre. Vemos entonces cómo, según Dussel, aparece la dialéctica de la "imagen" y la "semejanza":

"El hombre es imagen de Dios y en este sentido es apto para alcanzar la perfección. Dicha perfección es la divinización o semejanza con Dios. Entre la imagen y la semejanza media el ejercicio de una recta libertad. Se trata entonces de la dialéctica hebrea entre basar y ruaj, entre carne y espíritu, entre el hombre carnal y espiritual, entre el hombre terrestre y el celeste. Estamos en la más auténtica antropología cristiana, que ha sabido incorporar valiosos elementos de la antropología helénica, pero dentro de un horizonte estrictamente semitocristiano" 52 .

\section{La libertad del cristiano}

El tema de la libertad o libre albedrío humano, cuyo tratamiento resulta ineludible en cualquier reflexión de la antropología filosófica actual, se encuentra prácticamente ausente de la especulación filosófica anterior a Aristóteles, y es exclusivamente en el estoicismo, aunque sea para negarlo, donde recibe su tratamiento más formal. El concepto de libertad aparece en Grecia en contraposición al de servidumbre en el orden civil o político.

Algunos autores han creído ver en Platón una primera afirmación explícita del libre albedrío, sin embargo, habrá que esperar a Aristóteles para encontrar en el libro III de la Ética Nicomaquea, la distinción entre los actos que son hechos hékon, es decir, espontáneamente, sin ser coaccionado, y los que lo son ákon, sin voluntariedad, no libremente.

49 Cf. J. J. SANGUINETI, La antropología educativa de Clemente Alejandrino..., p. 240.

50 Cf. CLEMENTE DE ALEJANDRÍA, Stromata, IV, 27, 3 (FuP 15, p. 95).

51 E. DUSSEL, El humanismo helénico..., p. 76.

52 E. DUSSEL, El humanismo helénico..., p. 79. 
No obstante, con el estoicismo encontramos un primer planteamiento serio referido a aquellos actos "que están en nuestro poder", con el fin de negar el libre albedrío humano y extender a la esfera de lo moral el determinismo que para los estoicos regía el mundo físico ${ }^{53}$. Así, el tema de la relación entre causa y determinismo es uno de los más fundamentales en la filosofía estoica. El determinismo que defendían los estoicos se basaba en dos tesis: todo suceso y todo estado de las cosas tiene una causa y toda relación causal es necesaria, es decir, si se da la causa de algo, es necesario que ese algo también se dé.

La noción de libertad o libre albedrío se constituye como uno de los problemas en los que el Alejandrino hubo de implicarse puesto que se veía rodeado de ideas cercanas a la predestinación y al determinismo. Clemente de Alejandría se postula junto a Ireneo de Lyon como uno de los defensores más vehementes del libre albedrío.

En el siguiente texto, Clemente de Alejandría expone las consecuencias del determinismo fisista de Basílides y Valentín. En este sentido, todo el esfuerzo intelectual del maestro alejandrino consiste en salvar la libertad del hombre:

"Si eso es así, la fe no sería resultado de una libre elección, sino de un privilegio de la naturaleza; así tampoco sería responsable el que no cree, ni merecería un castigo justo; lo mismo que el creyente tampoco sería responsable. De esta manera, cuanto hay de personal y diverso realmente en nosotros por la fe o la incredulidad, no estará sometido ni a alabanza ni a reproche para quien bien razona, ya que todo se encuentra predeterminado por la necesidad natural, surgida del que tiene poder universal. Y si nosotros estamos gobernados por una fuerza natural, como por cuerdas, igual que los objetos inanimados, lo voluntario (hékon) y lo involuntario (ákon) resultan ser conceptos superfluos, al igual que el impulso que los dirige" ${ }^{54}$.

Estas consideraciones de Clemente son directamente dependientes de la Ética Nicomaquea. El maestro cristiano aplica estos conceptos al problema de la fe, puesto que si se tratara de una gnosis o iluminación gratuita no sería ya más el acto libre de una elección. Además, extrae la consecuencia, en el plano religioso, de que si se suprime el carácter libre de nuestros actos no habría lugar para el arrepentimiento, que concede el

53 Cf. M. M. BERGARA, "El aporte de los primeros siglos cristianos a la problemática del libre albedrío", en Revista de Filosofía y Teoría Política (28-29), 1992, pp. 13-14.

54 CLEMENTE DE ALEJANDRÍA, Stromata, II, 11, 1 (FuP 10, p. 77). 
A. Gerónimo. "Claves antropológicas del pensamiento de Clemente de Alejandría" en Palabra y Razón. Revista de Teología, Filosofia y Ciencias de la Religión. $\mathrm{N}^{\circ} 17$ Julio 2020, pp 76-99 https://doi.org/10.29035/pyr.17.76

perdón de las culpas ${ }^{55}$.

Clemente de Alejandría otorga un gran valor al papel de la razón. De hecho, dice al respecto: "pero hay que elegir lo que conviene a un bien superior, y lo mejor de todo es la inteligencia"56. No obstante, es sorprendente la cantidad de veces en las que insiste en el concepto de libertad, prestándole especial atención a la facultad electiva.

La idea central de Clemente es que Dios no es responsable de nuestras decisiones ni de nuestros actos, ni tampoco de nuestra opción por el mal. En la visión de Clemente, la libertad es la autodeterminación de la persona en sus actos:

"Ahora bien, en nosotros está el poder hacer aquello de lo que somos dueños, y también su contrario; por ejemplo el filosofar o no, creer o no creer. Así pues, por ser nosotros dueños por igual de cada uno de los dos actos contrarios, podemos investigar. De igual manera también podemos cumplir los mandamientos o no, a lo que sigue lógicamente alabanza o censura; y los que son castigados por causa de los pecados que han cometido, por ellos solos son castigados ${ }^{57}$. En verdad, lo que se ha hecho en el pasado y lo que se hiciere (en el futuro), si alguna vez se hace, no será algo que se pierda" 58 .

Es evidente la alusión de Clemente de Alejandría al tropos $\tau$ à $\dot{\varepsilon} \varphi ’ \hat{\eta} \mu \tilde{i} v$ ("lo que está en nuestro poder"), propio del pensamiento antiguo. Así, el problema de la libertad del hombre es, según lo entiende Clemente de Alejandría, la inclinación o tendencia que se da en el ser humano a realizar una mala elección. Por tanto, es fruto del pecado de Adán que nubla la inteligencia para que ésta no logre captar más fácilmente el bien al que debe tender. Por causa de la caída todo ha cambiado. La situación del pecador se resume desde entonces en esta palabra: esclavitud ${ }^{59}$.

El hombre sometido a las leyes de la biología y del cosmos, está condenado a la muerte, a los sufrimientos físicos. Las pasiones se despiertan y oscurecen el espíritu, le quitan la potencia. En esta situación, ¿sigue existiendo la libertad si por el pecado de Adán todos se han convertido en esclavos del mal ${ }^{60}$ Las Escrituras remiten constantemente a la posibilidad

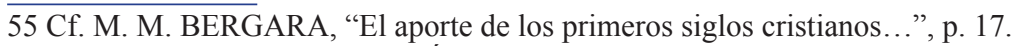

56 CLEMENTE DE ALEJANDRÍA, Stromata, IV, 149, 6 (FuP 15, p. 267).

57 Según O. Prunet, el castigo por los pecados admite diversos grados; cf. O. PRUNET, $L a$ morale de Clément d'Alexandrie et le Nouveau Testament, Études d'histoire et de philosophie religieuses 61: Paris, 1966, pp. 60-62.

58 CLEMENTE DE ALEJANDRÍA, Stromata, IV, 153, 1-2 (FuP 15, p. 275).

59 Cf. Rm 5, 12-14.

60 Cf. Rm 6, 20. 
de elegir y potencian la responsabilidad del hombre. Por un lado, la libertad se ha debilitado de forma irremediable, pero por otro lado, sigue estando al alcance del hombre ${ }^{61}$. El autor alejandrino participa de esta visión de la caída y del pecado.

El maestro de Alejandría es tan consciente de la importancia de la libertad ${ }^{62}$ que ve en los que la niegan una forma de ateísmo, cosa que, por otra parte, parece razonable. Y es que si el ser humano no fuera dueño de sus acciones y no pudiera elegir la forma en la cual vivir, toda la dinámica del plan de Dios quedaría paralizada.

En su obra ¿Qué rico se salvará? en el número 10, Clemente expresa la idea de que en el hombre estaba la elección, en cuanto a que es libre; y en Dios, la posibilidad de donar, en cuanto a que es Dios. Este texto muestra la libertad en función del don de Dios, con lo que se produce una apertura al tema teológico de la gracia. En opinión de Sanguineti, el "binomio libertad/gracia es indisociable" $"$. Por decirlo de otra manera, la capacidad natural de querer de forma libre implica algo diferente de la fuerza natural determinista, y así reclama la dinámica del don, o de lo gratuito, del mismo modo que sucede con el amor humano. Del modo contrario, no se entiende hablar de gracia si no existe libertad que la pueda aceptar.

Nuestro autor es conocedor de que el ser humano, antes de recibir a Cristo, estaba sometido a la esclavitud del espíritu (a los ídolos) y resignado a un estado de ignorancia (ante la verdad de la sabiduría), aspectos que se potencian de forma recíproca. Es cierto que el hombre es libre, pero experimenta fuerzas que provienen de la pasión y que lo llevan hacia el mal porque posee un espíritu debilitado. La humildad y la obediencia a Cristo, en la visión del Alejandrino, ayudarán al ser humano a volver a dominarse y quedar sanado. Cuando la fuerza interna del hombre se limita, la persona queda cada vez más dominada por las pasiones o los miedos sensibles. En esta situación se encuentra incapaz de poder dominarse y aunque no quiere caer, cae. Clemente se refiere a esta situación existencial aludiendo a los clásicos, tal y como podemos ver en este texto de Stromata II:

61 Cf. T. SPIDLIK, La espiritualidad del oriente cristiano..., pp. 137-138.

62 Resulta necesario en este punto distinguir dos conceptos. En primer lugar, "libertad" en el mundo antiguo se refiere a una noción eminentemente política, y alude a la ciudadanía de que gozan quienes no son esclavos, como se ha dicho anteriormente. En segundo lugar, la noción cristiana de libertad subjetiva ahonda significativamente el campo semántico de la noción de $\dot{\varepsilon} \lambda \varepsilon v \theta \varepsilon \rho i ́ \alpha$, que queda abierto por la Revelación.

63 J. J. SANGUINETI, La antropología educativa de Clemente Alejandrino..., p. 276. 
"Si no queremos participar de esa conducta, pero nos entregamos a la ira y cedemos ante las pasiones, pecaremos; o mejor, cometeremos una injusticia contra nuestra propia alma. El famoso Layo dice en la tragedia: nadie me ha ayudado a escapar de cuanto me reprochan, más bien la naturaleza me ha forzado, a pesar de que yo sea consciente. Esto significa andar tras las pasiones" ${ }^{\prime}$.

Este pasaje contiene reminiscencias aristotélicas. En la ética de Aristóteles, es la virtud de la continencia la encargada de dominar el alma y encauzarla hacia la recta razón. Para Clemente el ser humano es libre, pero seducido por el mal cae en esa seducción y se torna menos libre. Así sucedió con el pecado de Adán y de igual manera sucede en la vida de las personas. Ciertos mecanismos psicológicos dejan al hombre con poca capacidad para perseverar en el bien. Estas nociones nos recuerdan el concepto aristotélico del error trágico en Ética a Nicómaco. No obstante, el Alejandrino rechaza la idea de que la bondad y la maldad humanas vengan de fuerzas innatas que disminuirían la importancia de la elección:

"El gnóstico es, pues, piadoso, cuida primero de sí mismo, luego de los que están cerca, para que mejoremos lo más posible. En efecto, también el hijo se hace grato al buen padre cuando se muestra diligente a sí mismo e igual al padre, y el subordinado con el superior; ciertamente el creer y el ser obediente depende de nosotros. Alguien puede suponer que la causa del mal es la debilidad de la materia, o que los impulsos irreflexivos de la ignorancia no son voluntarios, o que las coacciones irracionales provienen de la impericia" ${ }^{95}$.

Este tópico del "cuidado de sí", cuyo precedente remoto se encuentra en el Alcibíades de Platón, es un tema capital en el estoicismo. Para los estoicos el cuidado de sí mismo se convierte en una forma de espiritualidad, y en una liberación de aquello que se depende. Por otra parte, el cuidado de sí mismo hace necesaria la presencia del otro. La filosofía es guía para el logro del gobierno de sí mismo y de los otros.

Clemente quiere conducirnos a razonar que la adhesión al bien no proviene de forma espontánea de la naturaleza, sino que requiere un acto admirable de la voluntad que vuelve su rostro hacia Dios, tal y como puede verse en las palabras del maestro alejandrino: "la salvación se obtiene por un cambio debido a la obediencia y no por naturaleza" ${ }^{66}$. En opinión de Postage, el cambio debido a la obediencia equivale a un acto libre y

64 CLEMENTE DE ALEJANDRÍA, Stromata, II, 63, 1-2 (FuP 10, pp. 179-181).

65 CLEMENTE DE ALEJANDRÍA, Stromata, VII, 16, 1-2 (FuP 17, p. 363).

66 CLEMENTE DE ALEJANDRÍA, Stromata, II, 115, 2 (FuP 10, p. 261). 
A. Gerónimo. "Claves antropológicas del pensamiento de Clemente de Alejandría" en Palabra y Razón. Revista de Teología, Filosofia y Ciencias de la Religión. $\mathrm{N}^{\circ} 17$ Julio 2020, pp 76-99 https://doi.org/10.29035/pyr.17.76

responsable del ser humano ${ }^{67}$.

\section{La apertura del hombre a la verdad}

Los textos de Clemente de Alejandría están repletos de ideas relacionadas con la verdad. De tal manera, observa que la raíz de la formación de las virtudes está en la actitud receptiva y sincera ante la verdad, que, a su vez, se trata de una actitud activa y no pasiva, que lleva necesariamente a buscar activa y sinceramente la verdad, una verdad que no deja de ser un don y no un mérito del hombre.

El Alejandrino quiere impulsar en sus discípulos lo que se puede llamar "el hábito contemplativo de la verdad"68. Para él, la ignorancia más perjudicial es la que se resiste con orgullo a reconocerse como tal. En esta línea nuestro autor se enfrenta a los paganos o a los herejes que discuten, manipulan la Escritura y falsean las verdades de la fe cristiana. Por ejemplo, en su crítica a los paganos, Clemente suele insistir en su insensibilidad frente a la verdad. De hecho, dedica el capítulo 10 del Protréptico al tema de la verdad, que es concretamente una exhortación a escucharla.

Entonces, ¿qué significa para él insensibilidad? Pues bien, la insensibilidad estaría ejemplificada en la mujer de Lot, que al detenerse y volver su mirada hacia Sodoma se convirtió en una estatua sin vida:

“AAcaso no habéis vuelto a la insensibilidad como de algún modo Níobe ${ }^{69}$, y sobre todo para que yo os dé un oráculo más misterioso, a la manera de la mujer hebrea (los antiguos la llamaban mujer de Lot)? Hemos oído decir que esta mujer fue convertida en piedra por enamorarse de Sodoma. Pero sodomitas son los ateos y los que se han vuelto a la impiedad, los de corazón duro y necios" ${ }^{\text {"70 }}$.

En este caso, para Clemente, la mujer de Lot representa la conversión a la impiedad o al mal (aunque para otros escritores de la época la mujer de Lot convertida en estatua de sal es una imagen de la Iglesia

67 Cf. J. P. POSTAGE, "On the Text of the Stromateis of Clement of Alexandria", en Classical Quarterly, 1914, p. 238

68 J. J. SANGUINETI, La antropología educativa de Clemente Alejandrino..., p. 108.

69 Níobe era hija de Tántalo y mujer de Anfión, rey de Tebas. Ella, orgullosa del número de sus hijos, se creyó superior a Letona, que sólo tenía dos, Apolo y Diana, que indignados con tal presunción mataron a flechazos a todos los hijos de Níobe, y los dioses, compadecidos de ella la transformaron en roca.

70 CLEMENTE DE ALEJANDRÍA, El Protréptico, 103, 4 (Se utiliza la edición bilingüe de M. MERINO, El Protréptico, Ciudad Nueva, Fuentes Patrísticas 21: Madrid, 2006, pp. 293-295). 
A. Gerónimo. "Claves antropológicas del pensamiento de Clemente de Alejandría" en Palabra y Razón. Revista de Teología, Filosofia y Ciencias de la Religión. $\mathrm{N}^{\circ} 17$ Julio 2020, pp 76-99 https://doi.org/10.29035/pyr.17.76

que, perseguida, permanece indemne) $)^{71}$.

Clemente quiere que la persona que no es creyente, como mínimo, busque la verdad sinceramente, y que se pare a reflexionar sobre las consecuencias que tiene adorar a los ídolos. Se queja de que los no creyentes apenas reflexionan en el momento de satisfacer sus pasiones, y en cambio, emplean mucho tiempo en pensar si conviene o no conviene creer, por lo cual Clemente les invita a hacer exactamente lo contrario:

"En efecto, hay que poner en duda, si uno se debe embriagar, por así decir; en cambio, vosotros os embriagáis antes de examinarlo. Y si uno puede ultrajar no os intriga, sino más bien con cuánta rapidez debéis maltratar. En verdad, únicamente preguntáis si hay que ser piadoso, y si hay que adherirse ahora a este sabio y a Cristo; ahora bien, pensáis entonces que eso es digno de reflexión y examen, sin entender que eso es lo que siempre conviene a Dios"72.

En estos textos, el Alejandrino pretende dar argumentos a los no creyentes para llevarlos a la fe. Se puede observar en ellos -según la mirada de Clemente-, un énfasis en el valor de la inteligencia, que no obstante, estima como importante la libertad ${ }^{73}$, y que termina con la persuasión del provecho de creer en Cristo. El maestro de Alejandría ha buscado ver cuál es la raíz más profunda que dificulta el acto de creer. Esta raíz está en la dureza del corazón y la ceguera del entendimiento.

La condición platónica de una vida justa como legitimación para observar la verdad es elevada al plano más personal del Evangelio. De esta manera Clemente no tiene motivos para despreciar a la sabiduría con el fin de llamar a los griegos a la fe. Únicamente introduce en ella la dimensión de la libertad y del compromiso moral.

También aborda el Alejandrino el tema de la inutilidad de la ciencia humana frente a la sabiduría divina; "¿no ha hecho Dios necia la sabiduría de este mundo?" 74 Sin embargo, estas palabras que asume como suyas no le conducen al desprecio de la filosofía griega, sino más bien a la crítica sobre su mal empleo. Clemente atribuye a los no creyentes que no reconocen a Dios el hecho de acabar en una pseudo-ciencia, es decir, en una sabiduría aparente, puesto que el Alejandrino piensa que deberían

71 Cf. A. ORBE, "La teología del Espíritu Santo", en Estudios Valentinianos, vol. IV, Analecta Gregoriana 158: Roma, 1966, p. 597.

72 CLEMENTE DE ALEJANDRÍA, El Protréptico, 95, 4 (FuP 21, p. 279).

73 Para estudiar el tema de la relación entre verdad y libertad; cf. J. J. SANGUINETI, El conocimiento humano. Una perspectiva filosófica, Palabra: Madrid, 2005, pp. 334-338.

74 Cf. CLEMENTE DE ALEJANDRÍA, Stromata, I, 88, 1 (FuP 7, p. 261). Clemente cita aquí 1 Cor $1,20$. 
asumir los conocimientos científicos en orden a la contemplación de la sabiduría.

En la perspectiva clementina resulta esencial la defensa de la sabiduría de la cruz, que, por otra parte, no implica en el mismo autor alejandrino una valoración negativa sobre la filosofía, sino un planteamiento más profundo de la contemplación filosófica, muy característico de la filosofía cristiana ${ }^{75}$.

La realidad es que Clemente debió vivir en sus carnes la incredulidad de los ambientes paganos intelectuales de la ciudad de Alejandría ante temas como la encarnación, pasión, muerte y resurrección de Cristo ${ }^{76}$. La reacción de nuestro autor es la de reprochar a los griegos su insensatez y la de presentar la dureza de corazón para explicar su banalización de la sabiduría. A este respecto, el siguiente escrito del Alejandrino resulta muy revelador:

“Así, pues, la presencia del Salvador no ha motivado a los insensatos, a los de corazón duro, ni a los incrédulos, sino a los sensatos, a los dóciles y también a los que creen. Pero los que no han querido obedecer a la llamada, separándose de los que han respondido voluntariamente a la misma, son necios, insensatos e incrédulos. Mas para los llamados sean judíos o griegos, Cristo es poder de Dios y sabiduría divina ${ }^{77}$. Ahora bien, ¿sería mejor interpretar la expresión no hizo Dios necia la sabiduría del mundo ${ }^{78}$ en el sentido de que no la hizo necia, para que no parezca que Dios es la causa de la dureza del corazón de aquellos, al hacer necia la sabiduría? Por el contrario, puesto que son realmente sabios, se hacen responsables en mayor medida de no haber creído el anuncio. En efecto, la elección y el rechazo de la verdad es libre" ${ }^{\text {". }}$.

Al ser rechazada la verdad que debía creerse por falta de fidelidad o de docilidad, la sabiduría racional se vuelve necia, ignorante. Para el Alejandrino, la verdad que no es asumida con las adecuadas disposiciones del corazón, tiende a oscurecerse.

Clemente ha querido poner de este modo las condiciones intelectuales necesarias para que se pueda dar el paso del paganismo a la verdad del cristianismo. El paso a creer, esto es, a la fe, puede suceder en un alma

75 Cf. J. J. SANGUINETI, La antropología educativa de Clemente Alejandrino..., p. 111.

76 Posiblemente fuera una experiencia cercana a la que vivió san Pablo en el Areópago de Atenas al predicar que Cristo había muerto y resucitado; cf. Hch 17, 22-34.

77 PCf. 1 Cor 1, 24.

78 Cf. 1 Cor 1, 20.

79 CLEMENTE DE ALEJANDRÍA, Stromata, I, 88, 6-8 - 89, 1 (FuP 7, p. 263). 
A. Gerónimo. "Claves antropológicas del pensamiento de Clemente de Alejandría" en Palabra y Razón. Revista de Teología, Filosofia y Ciencias de la Religión. $\mathrm{N}^{\circ} 17$ Julio 2020, pp 76-99 https://doi.org/10.29035/pyr.17.76

sensible ante la contemplación de la verdad.

\section{Influencia platónica en la antropología de Clemente de Alejandría}

Las obras de Clemente de Alejandría son, quizás, las que reflejan de una forma más fiel la filosofía platónica dentro del pensamiento que desarrollaron los primeros autores intelectuales del cristianismo en los primeros siglos de nuestra era.

Debido a que la inmensa mayoría de las religiones antiguas no tenían una preocupación moral, y únicamente la filosofía-desde Sócrates-, proponía una norma de vida, a ella se dirige Clemente. ¿Y cómo lo hace? Pues reproduciendo especialmente a Platón, que según su criterio es "el filósofo" por excelencia, puesto que su filosofía era la más repleta de valores religiosos. En opinión de M. C. Isart, si Clemente admira tanto a Platón es porque nadie antes había hablado mejor de Dios. En contraposición, con el estoicismo fue muy duro en este sentido porque materializó a la divinidad ${ }^{80}$, aunque tomara de él elementos de su moral ${ }^{81}$.

Una primera expresión de la influencia de Platón en nuestro autor se puede ver en la teoría de los dos mundos. Son numerosas las citas del Alejandrino referidas a los dos cosmos. Así pues, para Clemente, uno es el mundo sensible o visible y otro el mundo inteligible o invisible, y coloca entre los dos una distancia infinita ${ }^{82}$. De modo que si uno está ligado al mundo de los cuerpos sólo podrá captar el de los cuerpos. De ahí se deriva la necesidad de llegar al mundo invisible para captar la verdadera realidad, éste es el mundo en donde está el verdadero $\operatorname{ser}^{83}$.

Platón pensaba que el único modo de llegar al mundo inteligible era mediante el conocimiento, y más en concreto, la dialéctica. Esta ciencia es para Platón la ciencia del bien y de la verdad, el punto más elevado de la sabiduría, con la cual se accedería al mundo inteligible. No obstante, en el pensamiento de Clemente todo este saber es un instrumento útil como preparación previa ante el mundo inteligible. Por tanto, la filosofía y la dialéctica no serían suficientes para alcanzar el mundo de las ideas.

Bien es cierto que el cristianismo también utiliza la idea de los dos

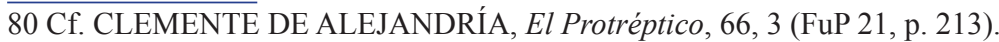

81 Cf. M. C. ISART, "Clemente de Alejandría y la filosofía griega" en Anuario de estudios filológicos, Vol. 15, 1992, p. 25.

82 Cf. J. MEIFORT, Der Platonismus bei Clemens von Alexandrien, Heidelberger Adhandlungen zur Philosophie und ihrer Geschichte, Vol. 17: Tubinga, 1928, pp. 11-19.

83 Cf. J. A. LLAMAS MARTÍNEZ, "Influencias platónicas en el pensamiento de Clemente de Alejandría”, en Educación XXI, Vol. 4, 2001, pp. 242-243. 
mundos, y Clemente se sirve de la filosofía platónica en este sentido, pero a diferencia de Platón, el Alejandrino introduce "un matiz religioso" 84 . De este modo, el mundo platónico inteligible abarca en Clemente el mundo de la fe. Además, hay otro punto diferencial entre nuestro autor y la teoría platónica. Para Clemente se establecen tres grados de conocimiento a recorrer. Llamas Martínez lo explica de manera convincente:

"En primer lugar estaría la esfera de los conocimientos sensibles, aquello que se muestra a nuestros sentidos. En un lugar intermedio estarían los conocimientos comprendidos por la antigua filosofía y la Antigua Profecía, toda esta esfera contiene conocimientos auxiliares, y a la que Clemente define como egkúklion paideía, por la que se accedería a la esfera del mundo superior, último grado y suprema verdad, en la que [...] ya sitúa Clemente el mundo de la fe" ${ }^{95}$.

En relación con el tema platónico de los dos mundos, estaría la influencia que ejerce Platón sobre nuestro autor en la cuestión antropológica de la relación cuerpo-alma. Para ambos, estas dos realidades corresponderían a cada uno de los dos mundos. El alma al mundo inteligible, el cuerpo al mundo sensible.

Cuando el Alejandrino trata la cuestión del alma racional y su creación en el hombre, se decanta por la tradición platónica y no por la estoica. Según Platón, el alma procede del mundo inteligible y se incorpora de forma violenta al mundo sensible. Sin embargo, en Clemente se observa una clara diferencia. El alma aparece por creación, y de forma natural se adhiere al cuerpo humano, posibilitando al hombre un dinamismo para la perfección.

El maestro alejandrino se ve forzado a acomodar el pensamiento cristiano al pensamiento filosófico de su tiempo cuando habla del alma y de su división tripartita, de la que Platón ya había hecho referencia anteriormente. Clemente se sirve de la adaptación que ya había iniciado Filón, sin renunciar al lenguaje introducido posteriormente por el estoicismo. El Alejandrino toma de Platón la triple división del alma ${ }^{86}$ : nous (alma racional), thymós (alma irascible) y epithymía (alma apetitiva). Pero Clemente elige la terminología paulina -que está influida en parte por el estoicismo-, a pesar de que el contenido es platónico, por lo que

84 J. A. LLAMAS MARTÍNEZ, "Influencias platónicas en el pensamiento de Clemente de Alejandría", p. 243.

85 J. A. LLAMAS MARTÍNEZ, "Influencias platónicas en el pensamiento de Clemente de Alejandría", p. 243.

86 Cf. L. RIVERA - A. VALENTINETTI, El libro y la carne (hermenéutica del libro), Universidad de Sevilla Secretariado de Publicaciones: Sevilla, 1998, pp. 96-97. 
prefiere entender al hombre perfecto y total como compuesto de tres elementos ${ }^{87}$ : sárx (cuerpo), psyché (alma racional) y pnéuma (espíritu). Al respecto dice: "por otra parte con el tres se podría entender la pasión, la concupiscencia y la razón; o también, la carne, el alma y el espíritu, según otra explicación" $" 88$.

Aunque el alma racional, igual que en el pensamiento de Platón, es la encargada de gobernar el cuerpo en Clemente, se da en él un intento por cristianizar el dualismo platónico introduciendo una cierta unidad dinámica en el hombre. Por tanto, según Llamas Martínez se añade una cierta novedad en el concepto de hombre aportada por los pensadores del siglo II, entre los que se encuentra Clemente, en el que hay una clara distinción entre psyché y pneúma ${ }^{89}$. De esta manera, en opinión de Fernández Ardanaz, el hombre -para el intelectual cristiano-, está compuesto de alma y cuerpo, en el que el término psyché significa el soplo divino, por el cual el hombre participa racionalmente de Dios, y queda proyectado dinámicamente a una participación superior, que vendría significada por el tercer elemento del que se compone el ser humano (pnéuma), que perfecciona y salva al hombre por la $\mathrm{fe}^{90}$.

Cabe destacar que Merino y Redondo ${ }^{91}$, sobre este mismo tema de la división del alma, discrepan con Meifort ${ }^{92}$, defendiendo que no se trata de una división tricotómica del alma en la estructura del hombre, como éste pretende, sino que Rohde ${ }^{93}$ ha demostrado que Platón se refería a tres clases diversas de ciudadanos. Por tanto, es mejor hablar de trinomía y no de tricotomía, puesta que esta última parte supone partes de un todo.

Dentro de la antropología, otro de los temas donde se puede ver una indudable influencia platónica es en la búsqueda de la semejanza con

87 Cf. J. A. LLAMAS MARTÍNEZ, "Influencias platónicas en el pensamiento de Clemente de Alejandría", p. 245

88 CLEMENTE DE ALEJANDRÍA, Strom., III, 68, 5 (FuP 10, p. 417). La primera división (pasión, concupiscencia y razón) recibe el nombre de trinómica y fue realizada por el pensamiento platónico-estoico, y la segunda (carne, alma y espíritu) alude a la que hace san Pablo en la $1^{\mathrm{a}}$ Carta a los Tesalonicenses, aunque en este caso invierte el orden de los tres miembros y sustituye “cuerpo" por carne”; cf. M. SPANNEUT, Le Stoïcisme des Pères de l'Église..., pp. 167-175; cf. J. BERNARD, Die apologetische Methode bei Klemens von Alexandrien. Apologetik als Entfaltung der Theologie, Erfurter Theologische Studien 21: Leipzig, 1968, pp. 135-136.

89 Cf. J. A. LLAMAS MARTÍNEZ, "Influencias platónicas en el pensamiento de Clemente de Alejandría", p. 245.

90 Cf. S. FERNÁNDEZ ARDANAZ, El mito del "hombre nuevo" en el siglo II: el diálogo cristianismo-helenismo, Fundación Universitaria Española: Madrid, 1991, p. 97.

91 Cf. M. MERINO - E. REDONDO, Clemente de Alejandría. El pedagogo, Ciudad Nueva, Fuentes Patrísticas 5: Madrid, 1994, p. 503.

92 Cf. J. MEIFORT, Der Platonismus bei Clemens von Alexandrien..., p. 25.

93 Cf. E. ROHDE, Psyche, Laterza: Bari, 1970, pp. 597-604. 
la divinidad. La mayor parte de los autores que han estudiado esta cuestión coinciden en la dependencia clara que presenta el maestro alejandrino de Platón, a pesar de que toda esta temática llega a Clemente por vías como la bíblica o la filoniana ${ }^{94}$.

Si queremos entender el aspecto de la semejanza con la divinidad es necesario matizar que, aunque los primeros intelectuales cristianos vieron en Platón un cierto monoteísmo, sin embargo, no es plenamente extrapolable la idea platónica de Dios a la idea de Clemente. Así pues, para el Alejandrino -influido en esta cuestión por el estoicismo y por la fe que profesaba-, Dios es un ser que se preocupa, que es providente y conduce la historia del hombre.

Ambos -Platón y Clemente- hablan de una especie de liberarse ético para poder llegar a lo divino y de la importancia de contemplarlo. No obstante, esto no basta. No son suficientes el conocimiento y la gnosis para acceder a Dios. Clemente afirma la existencia de una fe irracional que permita la divinización del gnóstico en Dios, argumento que se desconoce en Platón, en el que lo divino se encuentra en el punto más elevado de la dialéctica ${ }^{95}$.

La semejanza con la divinidad es para Platón el fin último. Por eso, la finalidad de unirse místicamente a la divinidad se lograría con la razón. Además, esta semejanza no implica un salir de la propia esencia del hombre. Según la visión de Llamas Martínez,

"Esta visión platónica de la semejanza tiene en Clemente algunos matices en los que difiere de Platón, y que son explicables en el contexto filosófico y religioso que le tocó vivir al alejandrino. Así, en la época helenística la semejanza con la divinidad sirvió para expresar el sentimiento religioso del momento. Toda filosofía tiene un telos, y Clemente busca el telos de la filosofía, que encuentra reflejado en el Platonismo Medio. La novedad de Clemente respecto de Platón consiste en que la razón no basta para alcanzar la semejanza, en contra de lo que opinaba Platón. Alcanzar la semejanza lleva implícita una experiencia religiosa. El creyente tiene que buscar constantemente en la fe esta semejanza. Es por la entrega amorosa a Dios por la que se alcanza dicha semejanza, para nuestro autor, y no basta con poner el pensamiento y la razón en el Ser Supremo. Para el alejandrino existen dos caminos para llegar a esta meta: la prudencia y reflexión personal, por una parte, y la praxis moral, por otra, que conlleva la purificación

94 Cf. J. A. LLAMAS MARTÍNEZ, "Influencias platónicas en el pensamiento de Clemente de Alejandría", p. 246.

95 Cf. J. A. LLAMAS MARTÍNEZ, "Influencias platónicas en el pensamiento de Clemente de Alejandría”, p. 246. 
de los apetitos como condición previa al alma para asemejarnos a Dios. De esta manera Clemente se aleja de la línea intelectualista platónica y se aproxima a la línea del neoplatonismo de Plotino, que entiende la semejanza más como una unión mística con la divinidad"96.

Clemente de Alejandría, dentro de esa visión místico-religiosa en la que entiende la semejanza, enumera una serie de virtudes necesarias para poder llegar a alcanzarla: la purificación, la carencia de necesidades, la liberación de las pasiones, la continencia, el verdadero amor, la mansedumbre, la piedad y la obediencia ${ }^{97}$.

Por tanto, se puede vislumbrar que el Alejandrino se desenvuelve en una esfera predominantemente espiritual, relacionando los contenidos éticos con la experiencia religiosa. El pensamiento de Platón es el motivo, pero las diferencias entre ellos son más que evidentes, puesto que Platón no excede el ámbito de la filosofía, ya sea en la dimensión gnoseológica o en la ética. El maestro de Alejandría realiza una verdadera cristianización del pensamiento platónico, interpretándolo de distintos modos ${ }^{98}$.

\section{Conclusiones}

El presente estudio presenta las claves antropológicas del pensamiento de Clemente de Alejandría que son de evidente interés sistemático e histórico en el campo de la patrística y de la filosofía griega en general. Por tanto, se trata de un estudio sinóptico, dirigido a perfilar una visión de conjunto de la antropología de Clemente de Alejandría.

Ciertamente la antropología ha sido el caballo de batalla de la filosofía y la teología en todos los siglos, pero especialmente en los primeros siglos del cristianismo, siendo el Alejandrino el que inauguró la filosofía cristiana evidenciando la total complementariedad entre fe y filosofía. No obstante, para Clemente de Alejandría el Evangelio era poseedor del título de la verdadera filosofía, por eso interpretaba la filosofía griega como una instrucción propedéutica a la fe cristiana y una preparación para el Evangelio.

Este estudio ofrece la visión antropológica de Clemente de Alejandría en temas de indudable interés como la disposición cuerpo-

96 J. A. LLAMAS MARTÍNEZ, "Influencias platónicas en el pensamiento de Clemente de Alejandría", p. 248.

97 Cfr. CLEMENTE DE ALEJANDRÍA, Stromata, VII, 13, 1-4 (FuP 17, pp. 357-359).

98 Cf. J. A. LLAMAS MARTÍNEZ, "Influencias platónicas en el pensamiento de Clemente de Alejandría", p. 249. 
alma, el fin del hombre, el tema de la libertad y la apertura del hombre a la verdad. Además, concluye con una revisión y análisis sobre la influencia de Platón en la antropología del maestro cristiano. En este trabajo las citas textuales de las obras de Clemente de Alejandría han servido de referencia base y nos han guiado en el desarrollo de su antropología. 
